\title{
REFORMA E DESAFIOS DA EDUCAÇÃO SUPERIOR: O PROCESSO DE BOLONHA DEZ ANOS DEPOIS
}

Neste artigo, pretende-se oferecer um quadro compreensivo do Processo de Bolonha e de seus resultados. Dez anos se passaram desde o início da implementação desse projeto educacional na Europa. Após caracterizar os principais elementos dessa reforma, é apresentada uma análise do ensino superior na Alemanha pós-Bolonha. ${ }^{1}$

No contexto contemporâneo, a educação superior vem passando por enormes transformações em meio à globalização e ao advento da sociedade do conhecimento. Podem-se citar, como exemplos de significativo impacto social, as mudanças que ocorrem na China e na Índia, mas uma verdadeira revolução se deu na Europa, transformando sistemas consolidados de ensino superior (Altbach, Reisberg \& Rumbley, 2009). Responsável por essas mudanças foi a persistente disposição dos governos nacionais de seguirem as orientações do que se convencionou chamar de Processo de Bolonha.

Tal processo consistiu em uma proposta ousada de aperfeiçoamento dos sistemas de ensino superior dos países europeus. Como reforma, pretendeu e pretende ser uma resposta a diversos problemas enfrentados, em grau e amplitude distintos, pelos países da região e um instrumento de fortalecimento da União Europeia (UE). Esse dinamismo visava, essencialmente, aumentar a capacidade europeia de competição no cenário de globalização.

Com o objetivo de reconhecer e analisar os desafios que essa reforma almejava confrontar e os problemas que objetivava superar, propõem-se quatro questões centrais, que se concentram, privilegiadamente, no caso alemão: 1) Quais eram os objetivos e como se implementou o Processo de Bolonha?

2) Por que a Alemanha aderiu ao Processo de Bolonha, uma vez que seu sistemade ensino superior fora um modelo acadêmico e referência internacional? 3) Como foi possível realizar uma reforma de tão amplas proporções considerando a descentralização e a autonomia que caracterizam o sistema de ensino superior na Alemanha?

4) Dez anos depois, que questionamentos são suscitados pelo processo de implementação dessa reforma? 
Os tratados da UE especificavam que a educação é uma atividade sob jurisdição dos Estados-membros e, portanto, não seria matéria de regulamentação pela União. Com isso, os sistemas de ensino superior permaneciam à margem da integração europeia, mesmo com o crescimento de programas de intercâmbio e de apoio à mobilidade estudantil e docente na Europa, como os programas Sócrates ${ }^{2}$ e Erasmus ${ }^{3}$ (Erasmus Programme, 2010).

Em 1998, os ministros responsáveis pela educação superior da Grã-Bretanha, da Alemanha, da Itália e da França, reunidos nesse último país, pronunciaram-se, na Declaração de Sorbonne, a favor da criação de uma Área de Educação Superior Europeia (European Higher Education Area). Esse documento foi a pedra fundamental do processo posterior de reforma sancionada em 1999 com a Declaração de Bolonha.

A partir daí, o processo adquiriu um dinamismo extraordinário. Uma série de conferências e de comunicados, que se realizava a cada dois anos, foi operacionalizando e consolidando as metas da Reforma de Bolonha, e levou à adesão de número sempre crescente de países. Atualmente há 47 países signatários da reforma. O Processo de Bolonha, portanto, foi uma decisão eminentemente política que passou a ser vista como inevitável e irreversível pelos principais atores dos diferentes sistemas nacionais europeus.

O desdobramento dessas ações impactou a política educacional dos países e criou uma dinâmica destinada a coordenar as transformações nacionais em um movimento continental abrangente. Mesmo assim, o Processo de Bolonha não foi subordinado a nenhuma organização supranacional. O procedimento de implementação das mudanças era responsabilidade da política educacional de cada país, permanecendo, portanto, uma margem de autonomia para a configuração de cada sistema de ensino superior.

O Processo de Bolonha só pode ser compreendido se for analisado em toda a sua complexidade e ousadia; não só por meio das metas propostas e dos diferentes interesses e razões que as animavam, mas também por meio das tensões e dos conflitos que permearam a consecução dessas metas.

A reforma do ensino superior na Europa teve apoio em duas outras iniciativas: a Estratégia de Lisboa, um plano de desenvolvimento estratégico da UE aprovado pelo Conselho Europeu, em Lisboa, em março de 2000 (Conselho Europeu de Lisboa, 2000), e a Agenda de Modernização, uma resolução de 2007 do Conselho da União Europeia sobre a reforma das universidades do continente (Conselho da União Europeia, 2007). Essas iniciativas visavam construir uma Europa com uma economia baseada no conhecimento. Propunham o aumento dos gastos públicos e privados, da qualificação de professores, a promoção da formação continuada, a atratividade dos sistemas de ensino superior, entre outros. 


\section{O PROCESSO DE FORMULAÇÃO DE UMA REFORMA DE PROPORÇÕES CONTINENTAIS}

\section{Declaração de Sorbonne (1998)}

O ponto de partida do Processo de Bolonha não ocorreu na Itália, mas na França. Por ocasião do jubileu de 800 anos da Universidade de Paris, reuniram-se na Sorbonne, em maio de 1998, os ministros da Educação da França, da Alemanha, da Itália e da Inglaterra para elaborar uma "declaração conjunta" (joint declaration), a Declaração de Sorbonne. O objetivo era "promover a harmonização das estruturas dos sistemas de ensino superior" (Sorbonne Joint Declaration, 1998).

A declaração previa, para isso, a construção de estruturas de qualificação comuns, um sistema baseado em dois ciclos e a promoção da mobilidade de estudantes e professores. Com essas orientações, os ministros mostravam sua disposição para fomentar a construção de uma sociedade do conhecimento em âmbito europeu. A declaração teve forte repercussão, resultando na mobilização dos ministros da Educação europeus para a reunião que ocorreu em 1999 em Bolonha, na qual foi ratificada a proposta de reforma, com a presença de 29 países europeus (Witte, 2006a).

\section{Declaração de Bolonha (1999)}

No encontro de Bolonha foram definidas as principais orientações para as mudanças dos sistemas de ensino superior europeus visando ao aumento da competitividade dos referidos sistemas de educação e à promoção da mobilidade e da empregabilidade no espaço europeu. Seis linhas de ação foram estabelecidas para criar um Espaço Europeu de Educação Superior até 2010 (Bologna Declaration, 1999):

- adoção de um sistema de graus facilmente compreensíveis e comparáveis;

- adoção de um sistema baseado em dois ciclos de ensino, o Bachelor e o Master;

- estabelecimento de um sistema de acumulação e de transferência de créditos (tal como o European Credit Transfer System (ECTS), já em uso nos programas Sócrates e Erasmus);

- promoção da mobilidade de estudantes, docentes, investigadores e outros trabalhadores, removendo os obstáculos administrativos e legais ao reconhecimento de diplomas;

- promoção da cooperação europeia na avaliação da qualidade da educação superior;

- promoção do Espaço Europeu de Educação Superior.

\section{Declarações posteriores a Bolonha}

Desde Bolonha, os ministros da Educação de cada país signatário da declaração se reuniram a cada dois anos, quando emitiam comunicados que resumiam os 
progressos até então efetuados e estabeleciam novas prioridades de curto e longo prazos. Essas reuniões eram preparadas pelo Bologna Follow-up Group (BFuG). ${ }^{4}$

As declarações e os comunicados dos demais encontros são apresentados a seguir, em uma cronologia que destaca as principais decisões tomadas para fazer avançar a reforma do ensino superior na Europa.

Há uma linha de continuidade dos princípios e objetivos que reforça a expansão das metas do Processo de Bolonha. Pode-se perceber que, de 1999 até 2005 , foram sistematicamente incorporadas novas demandas à proposta inicial, que consistia em estrutura comum de qualificação, sistema baseado em dois ciclos de formação e promoção da mobilidade de estudantes e professores. Uma segunda linha de continuidade se refere à crescente adesão do número de países signatários. Em 2010, já somavam 47.

1998 Declaração de Sorbonne Mobilidade de estudantes e professores.

Implementação de um sistema comum de dois ciclos.

Promoção da Europa do conhecimento.

1999 Declaração de Bolonha Implementação do sistema de créditos (ECTS).

Títulos facilmente legíveis e comparáveis.

Dimensão europeia da educação superior e fomento à mobilidade.

Cooperação europeia para a garantia da qualidade.

2001 Comunicado de Praga Aprendizagem ao longo da vida.

Inclusão da dimensão social.

Envolvimento de Instituições de educação superior e de estudantes.

Promoção do Espaço Europeu de Educação Superior.

2003 Comunicado de Berlim

Vínculos mais estreitos entre investigação e educação.

Inclusão do doutorado com $3^{\circ}$ ciclo.

Marco europeu de qualificações (EQF).

Reconhecimento das titulações e dos períodos de estudo

(Suplemento ao Diploma).

Garantia de qualidade no nível institucional, nacional e europeu.

2005 Comunicado de Bergen Consolidação da dimensão social.

Marcos nacionais de qualificações.

Concessão e reconhecimento de títulos conjuntos.

Parâmetros e diretrizes para a garantia de qualidade.

2007 Comunicado de Londres

Compromisso de elaboração de planos de ação nacionais com um controle efetivo sobre a dimensão social.

Estratégia para melhorar a dimensão global do Processo de Bolonha.

Criação de um Registro Europeu de Qualidade. 
2009 Comunicado de Leuven

Meta de $20 \%$ até 2020 para a mobilidade estudantil.

Quadro de qualificações nacionais até 2012.

Metas nacionais para a dimensão social até 2020.

Educação continuada como responsabilidade pública com

base em parcerias.

Qualidade como foco importante para Área de Educação

Superior Europeia.

Ampliar o diálogo de políticas globais por meio do Fórum de Bolonha.

Figura 1: Cronologia do Processo de Bolonha

Fonte: Eurydice/EACEA, 2010.

Novas ênfases foram incluídas posteriormente na reforma: 1) ênfase em estratégias de aprendizagem ao longo da vida, ou educação continuada (lifelong learning); 2) necessidade de se voltar para a dimensão social do processo, envolvendo mais ativamente grupos desprivilegiados; 3) incentivo à empregabilidade (London Communiqué, 2007).

Tanto os objetivos iniciais quanto as novas orientações acrescentadas podem ser interpretados como pretensão a construir uma política pública europeia para a educação superior, embora a implementação do processo continuasse a depender da política educacional de cada um dos países signatários.

O ano de 2010 foi decisivo para o Processo de Bolonha, pois, nesse ano, deveria estar consolidado o Espaço Europeu de Educação Superior. A Conferência de Jubileu ocorreu em março de 2010 em Budapeste e em Viena, na qual foi reafirmada a Declaração do Espaço Europeu de Educação Superior. A próxima reunião deverá ser realizada em abril de 2012 em Bucareste. O tema será a retomada das linhas diretrizes do Comunicado de Louvain. Nesse encontro, os ministros decidirão prosseguir com a reforma até 2020 e estipularão metas para o crescimento da mobilidade estudantil. Também deverá ocorrer a expansão da dimensão social com a intensificação da inclusão de grupos subrepresentados (Budapest-Vienna Declaration, 2010).

\section{ORGANIZAÇÃO DO SISTEMA DE ENSINO SUPERIOR EUROPEU E A MOBILIDADE NO CONTEXTO DO PROCESSO DE BOLONHA}

\section{Nova estrutura de ensino e implementação do sistema de ciclos e de créditos}

A formação no ensino superior por meio de ciclos denominados Bachelor e Master é uma das características principais da proposta de reforma do Processo de Bolonha. Segundo Erichsen (2007: 30), os ciclos foram uma das soluções en- 
contradas para promover e facilitar a mobilidade e o reconhecimento de qualificações para a harmonização das estruturas de ensino superior na Europa. De acordo com a meta prevista, até 2010 todos os países signatários da Declaração de Bolonha deveriam ter um sistema de ensino superior organizado em ciclos.

O Bachelor, com duração de três a quatro anos, tem como objetivo preparar os estudantes para o mercado de trabalho europeu oferecendo um nível de qualificação apropriado. O segundo ciclo, denominado Master, tem duração de um ano e meio a dois anos de formação (excepcionalmente, pode levar apenas um ano). Esse segundo ciclo foi concebido originalmente como o momento inicial da formação para a pesquisa, mas vem se desenvolvendo e se consolidando como complementar ao Bachelor na formação do profissional de nível superior (Erichsen, 2007: 34; Ministry of Science, Technology and Innovation, 2005).

O doutorado foi incluído como um terceiro ciclo no Comunicado de Berlim, em 2003, com duração de três a quatro anos letivos (Berlin Communiqué, 2003). No Comunicado de Bergen, foi reforçada a importância de criar uma sinergia entre o Espaço Europeu de Educação Superior e o Espaço Europeu de Pesquisa (Bergen Communiqué, 2005). De acordo com Erichsen, "muitos professores atualmente consideram o doutorado o primeiro ciclo de formação de pesquisadores nas diversas áreas do conhecimento". ${ }^{5}$ Ele permanece como ciclo a ser oferecido exclusivamente pelas universidades.

Nesse contexto, fica evidente a diferença entre o Master europeu e o mestrado brasileiro. O mestrado no Brasil serve para ampliação e aprofundamento da qualificação profissional, mas não leva à habilitação profissional específica. Antes é visto, em sua modalidade acadêmica, como o primeiro momento da formação do pesquisador e como propedêutico ao doutorado. É claro que, na modalidade de mestrado profissional, as diferenças tendem a desaparecer, mesmo que este também não seja complemento de habilitação profissional.

Reorganizar os cursos no modelo Bachelor e Master exigiu uma reformulação dos currículos e dos processos de aprendizagem. As decisões e recomendações do Processo de Bolonha alertavam para que não houvesse apenas a renomeação de antigos cursos e currículos, mas sim a criação de estruturas curriculares que atendessem às exigências de formação de profissionais para o ingresso no mercado de trabalho europeu, sempre mais dinâmico.

Além da introdução dos ciclos - e complementar a eles -, foi importante o estabelecimento de um sistema de créditos para promover o reconhecimento dos estudos. O sistema de créditos - European Credit Transfer System (ECTS) - é fundamental para possibilitar a comparabilidade e a mobilidade de alunos entre cursos, instituições e currículos e para a consolidação do Espaço Europeu de Educação Superior. Baseia-se no trabalho, medido em número de horas de atividade, que o estudante deve efetuar para ser aprovado nas várias unidades curriculares do curso (ECTS, 2004). 
Os cursos, de qualquer um dos ciclos propostos pelo Processo de Bolonha, devem permitir a comparabilidade com base nos créditos ECTS alcançados. Há certa flexibilidade na quantidade de créditos necessários para a formação no primeiro e no segundo ciclos. De modo geral, no primeiro ciclo, os alunos devem cumprir de 180 a 240 créditos ECTS (de três a quatro anos). Ele é seguido pelo ciclo Master, que tem de 60 a 120 créditos (de um a dois anos). Um crédito ECTS equivale a 25 ou a 30 horas. O número de créditos necessários a cada ciclo está relacionado à formação e aos objetivos que as instituições e os cursos almejam atingir. Quando o primeiro ciclo é realizado com 240 créditos (quatro anos), segue-se um segundo ciclo de 60 créditos (um ano). É sugerido que a formação nos dois primeiros ciclos não ultrapasse cinco anos, ou 300 créditos (ECTS, 2004). Quanto ao doutorado, não é exigido um número de créditos predefinidos (Bergen Communiqué, 2005).

\section{Qualificações de cada ciclo}

Na Conferência de Bergen, em 2005, foi proposto um quadro comum de qualificações. Essa estrutura deveria facilitar a comparação entre os diferentes sistemas, permitindo uma harmonização de resultados (habilidades ou competências dos alunos), sem implicar homogeneização programática, promovendo a diferenciação de objetivos para cada ciclo, diferenciando níveis de aprendizagem e de capacidade.

Com base na definição prévia de competências que os alunos deveriam desenvolver para completar cada um dos ciclos do ensino superior, foi elaborado o quadro de qualificações. Entre algumas competências esperadas, merecem destaque, por exemplo: 1) no Bachelor, a capacidade de coletar e de interpretar dados relevantes da área de estudo, assim como emitir julgamentos que incluem reflexão sobre questões relevantes de natureza social, científica ou ética; 2) no Master, a habilidade para integrar diversos conhecimentos, lidar com a complexidade e formular julgamentos com informações incompletas ou limitadas, mas que inclui reflexão sobre responsabilidades éticas e sociais relacionadas à aplicação do conhecimento e às decisões; 3) no doutorado, espera-se que o estudante contribua, por meio de uma pesquisa original, para o alargamento da fronteira do conhecimento, com o desenvolvimento de um conjunto significativo de trabalhos, alguns dos quais aptos à publicação nacional ou internacional (Bergen Communiqué, 2005; Ministry of Science, Technology and Innovation, 2005).

\section{Suplemento ao diploma}

Um instrumento fundamental para possibilitar e promover a comparabilidade da formação entre cursos e a mobilidade foi a criação do suplemento ao diploma. O objetivo é facilitar a informação necessária ao reconhecimento - acadêmico e profissional - de qualificações: diplomas, graus e certificados. 
Acrescenta ao diploma original informação detalhada sobre a natureza, o nível, o contexto e o conteúdo dos estudos realizados pelo aluno. Destina-se a facilitar a mobilidade de alunos valendo-se de informações sólidas e precisas sobre todos os tipos de qualificação. Deve ser emitido na língua original e em uma língua de ampla divulgação na UE, sobretudo o inglês.

Cursos diferentes podem, assim, ser comparados considerando as capacidades que desenvolvem. Do mesmo modo, cursos semelhantes, da mesma área ou disciplina, podem se diferenciar ao adotar diferentes enfoques, especialidades e capacidades.

A comparabilidade dos estudos realizados nas diferentes instituições em que ocorre a mobilidade é reforçada pela referência ao histórico descritivo da formação do estudante. O emprego de quadros de qualificação comum e o suplemento ao diploma são, portanto, as principais formas adotadas para promover maior harmonização entre os sistemas de ensino superior dos países envolvidos no Processo de Bolonha (Prague Communiqué, 2001).

\section{Qualidade e avaliação}

Outra preocupação central do Processo de Bolonha para a garantia de qualidade dos cursos foi a proposta de estabelecimento de sistemas de avaliação interna e externa e de acreditação. Segundo o Comunicado de Berlim, há dois significados para a expressão "garantia de qualidade": desenvolver a qualidade de um curso ou instituição e dar garantias dessa qualidade a terceiros. A designação mais corrente para o processo relativo ao primeiro significado é "avaliação", ao passo que, para o segundo, é “acreditação” (Erichsen, 2007: 35-41).

Apesar da tradição de autonomia das universidades europeias, com Bolonha as Instituições de Ensino Superior (IES) tiveram de se ajustar aos procedimentos e às orientações da certificação de qualidade, definidas no quadro comum de qualificações de referência pela Rede Europeia para a Garantia da Qualidade na Educação Superior (European Association for Quality Assurance in Higher Education) (ENQA, 2005). Essa rede reúne os principais organismos de acreditação - governamentais e privados - dos Estados-membros, com a finalidade de fazer circular informação, experiências, boas práticas e novos desenvolvimentos no campo da certificação da qualidade.

As IES devem, consequentemente, criar sistemas próprios de garantia e desenvolvimento de qualidade, baseados na rede ENQA. Os instrumentos para isso são a avaliação e a acreditação. A avaliação refere-se às instituições, às pesquisas realizadas, aos cursos oferecidos, à gestão, aos serviços, entre outros fatores, constituindo-se em um processo autorreferencial. O processo de acreditação deve avaliar os programas e instituições por meio da avaliação interna e de uma avaliação externa realizada por agências especializadas, e seus resultados devem ser publicados (Berlin Communiqué, 2003). 
Assim, acreditação/certificação (para fora) e avaliação (para dentro e para fora), apesar de serem processos distintos, são complementares. Segundo Erichsen (2007: 39), o importante é que ambos os procedimentos devem servir para a garantia da qualidade do sistema de ensino superior.

\section{Lifelong learning}

Com base no Comunicado de Praga, e reafirmada nos demais comunicados, a formação foi compreendida como uma etapa ao longo da vida (lifelong learning). A tradicional expressão "educação para toda a vida" vem sendo, progressivamente, substituída por outra: "educação por toda a vida". A aprendizagem não deveria se esgotar na estrutura regular da oferta de educação, mas englobar um conjunto de outras atividades de formação: programas de mobilidade, e-learning, investigação e educação vocacional.

Para a concretização desse "espaço de aprendizagem", foi proposta a flexibilização da oferta de cursos com a criação de parcerias entre os prestadores de serviço educativo (escolas, universidades, institutos politécnicos, entre outros) e a sociedade civil (empresas, associações locais etc.). As necessidades do mercado de trabalho deveriam servir como referência em campos diferenciados, tornando as ofertas de aprendizagem mais acessíveis e facilitando também a aprendizagem no local de trabalho (Prague Communiqué, 2001).

\section{Mobilidade}

Mobilidade é objetivo primordial do Processo de Bolonha. Em sua proposta de harmonização dos sistemas de ensino superior, esse processo se baseia na tradição europeia da mobilidade acadêmica. Frey (2009: 7) aponta como exemplo clássico Erasmo de Roterdã (1466-1536). Nascido em Roterdã, estudou em Paris, fez o doutoramento em Turim, desenvolveu atividades docentes em Cambridge, foi pesquisador na Universidade de Freiburg e viveu seus últimos anos em Basel. Erasmo corporificou, já no século XVI, o verdadeiro ideal de educação e pesquisa. Foi o protótipo do homem moderno educado.

A implementação de uma estrutura de ensino superior comum a diversos países e baseada em ciclos, o estabelecimento de um sistema europeu de acúmulo e de transferência de créditos, um quadro comum de qualificações relativas a cada ciclo, o suplemento ao diploma, tudo isso foram medidas importantes para a promoção da mobilidade de estudantes, professores e profissionais graduados (Sorbonne Joint Declaration, 1998; Bologna Declaration, 1999). No entanto, muitas barreiras ainda impedem uma real mobilidade acadêmica europeia. De acordo com o BFuG, os maiores impedimentos estão relacionados à obtenção de vistos e de permissões de residência e de estágios, ao reconhecimento de qualificações e à falta de incentivos financeiros (bolsas e empréstimos para estudantes). 
A busca de soluções e o aprimoramento para garantir a mobilidade internacional podem ser constatados pelas diversas iniciativas de instituições e associações, como a campanha a favor da mobilidade estudantil Let's Go, promovida pela União dos Estudantes Europeus (European Student's Union, 2006). Todavia, o maior suporte para a efetivação da mobilidade ainda são os programas financiados pela UE, cujos principais são: Comenius, Leonardo da Vinci, Grundtvig e os voltados especificamente para a educação superior, Erasmus e Erasmus Mundus, e Tempus (Morhard, 2005; Erasmus Programme, 2010).

Dos três programas, o de maior destaque é o Erasmus. A maior mobilidade acadêmica durante os períodos 1987-1988 e 2008-2009 ocorreu em cinco países: Alemanha, França, Espanha, Itália e Reino Unido. Esses países também são os responsáveis pela maior parte da hospedagem dos alunos participantes no Erasmus. Tal concentração indica limites para a efetiva mobilidade de estudantes e docentes pela Europa, em especial no total dos 47 países parceiros do programa de reformas do Processo de Bolonha. Entre os países com menor mobilidade estão a Áustria, a Grécia e a Estônia (Erasmus Programme, 2010).

Ainda não há dados consolidados sobre mobilidade, mas os que estão disponíveis revelam fatos significativos. O principal deles é que há muitas diferenças na mobilidade entre os países. De modo geral, ela ainda está aquém do esperado. De 18 países, menos de 3\% dos estudantes têm alguma experiência de estudo em uma instituição estrangeira.

\section{IMPLEMENTAÇÃO DO PROCESSO DE BOLONHA NA ALEMANHA: PROBLEMAS E DESAFIOS DEZ ANOS DEPOIS}

Para responder às perguntas formuladas na introdução, devem-se realizar duas tarefas. Primeiro, compreender as razões apontadas pelos diferentes atores sobre a decisão de adotar o Processo de Bolonha; depois, analisar a realidade desse processo valendo-se da visão de diferentes atores sociais. Os atores são governamentais, especialmente o Ministério Federal de Educação e Pesquisa (Bundesministerium für Bildung und Forschung - BMBF) e a Conferência dos Secretários de Educação e Cultura dos Estados Alemães (Kultusministerkonferenz - KMK); os institucionais, como o Conselho de Reitores das Universidades Alemãs, entidade de representação das universidades (Hochschulrektorenkonferenz - HRK) e das reitorias das universidades; e atores sociais como professores e alunos e seus órgãos de representação (Brändle, 2010). 


\section{A REFORMA DO ENSINO SUPERIOR NA ALEMANHA}

\section{O modelo Humboldt de Universidade na Alemanha}

A reforma da universidade empreendida por Wilhelm von Humboldt, em 1810, serviu como exemplo inconteste por mais de cem anos, tornando-se referência para as universidades modernas e sendo difundida em todo o mundo.

De acordo com Nybom:

Sob a luz da história, não há dúvida de que a inovação institucional (a universidade humboldtiana em 1810) foi uma das mais bem-sucedidas reformas institucionais da pesquisa e da educação superior. Ela é responsável não somente pela atordoante explosão de criatividade e de produtividade que caracterizou a academia alemã e a vida científica nos 110 anos seguintes, mas também por sua imediata e maciça emergência como "modelo". Em menos de meio século, a Friedrich-Wilhelms-Universität de Berlim tornou-se um modelo de instituição indisputável para praticamente todos os sistemas universitários do mundo (Nybom, 2003: 145).

A concepção de Humboldt sobre a universidade tinha como princípios norteadores a formação do espírito humano pela ciência "na solidão e na liberdade" da vida acadêmica, isto é, autonomia institucional; a garantia da unidade do ensino e da pesquisa; a elevação da faculdade de filosofia a um papel central na organização da universidade; e a busca de uma nova relação entre professores e alunos, com caráter tutorial (Neves, 1998).

Uma característica particular do ensino superior proposto era o grau de liberdade dado aos estudantes para sua formação. Não havia um currículo com disciplinas previamente estabelecidas e que devessem ser realizadas para a conclusão do curso, ficando portanto a critério dos alunos a escolha das disciplinas para sua formação. Desde a reforma de Humboldt, a universidade alemã passou a ser considerada uma instituição do Estado, o que lhe garantia financiamento público, mas mantendo autonomia nas decisões referentes à sua missão no campo do ensino e da pesquisa.

A originalidade desse modelo influenciou sistemas de ensino superior como o norte-americano e o inglês. Entretanto, importantes modificações foram feitas nos Estados Unidos, que, desde cedo, criaram modalidades institucionais diferentes para as distintas funções do ensino superior. Lograram, dessa forma, combinar altíssimas taxas de escolarização superior (undergraduate level) com a excelência do nível universitário (graduate level) que vincula o ensino à pesquisa (Teichler \& Wasser, 1992).

O modelo original de Humboldt na Alemanha sofreu mudanças gradativamente. A transformação da universidade em "universidade de massa" alterou o equilíbrio entre suas diferentes funções e comprometeu sua missão clássica. As universidades foram compelidas a enfatizar a formação profissional, o que acarretou uma enorme expansão da área de ensino, produzindo zonas de conflito com a atividade de pesquisa. Esta também sofreu mudanças 
radicais, deixando de ser um processo de trabalho isolado de uns poucos cientistas e passando a ser um processo de trabalho coletivo de grupos e de redes. A ciência foi perdendo, aos poucos, sua função básica de "formação do espírito humano" e transformou-se em fator produtivo, com funções econômicas e políticas. A universidade, por sua vez, passou a ser multifuncional, diversificando o ensino e ampliando a prestação de serviços e a extensão (Neves, 1998).

A expansão do ensino superior levou à diversificação da oferta de educação superior com a criação das escolas superiores tecnológicas, as Fachhochschule. O modelo de educação superior alemão no fim do século XX caracterizava-se, basicamente, como um sistema dual constituído, de um lado, pelas universidades, e, de outro, pelas escolas superiores tecnológicas. Essas instituições tinham como objetivo oferecer uma formação direcionada ao mercado de trabalho. Uma diferença fundamental entre as universidades e essas instituições reside no fato de que apenas as primeiras podem oferecer a formação doutoral (Promotionsrecht).

Os cursos de graduação na universidade da Alemanha levavam a três diferentes habilitações: o diploma, o Magister e a formação de professores (Diplom, Magister, Lehramt). Os requisitos para a conclusão da graduação e a obtenção do diploma que garantia o acesso ao doutorado consistiam em duas provas. A primeira era realizada na metade da graduação; a segunda, final, levava à conclusão do curso. Não havia cursos de mestrado na estrutura da universidade alemã. Esses diferentes cursos de graduação tinham em comum o longo período de formação. A média de anos para a formação no modelo tradicional girava em torno de seis anos, e a taxa de evasão mostrava-se alta, cerca de $28 \%$ (Winter, 2009).

Como resultado das transformações do contexto econômico e político europeu e das necessidades do mercado de trabalho, os cursos tradicionais começaram a ser vistos como inapropriados. Verificava-se um descompasso entre a formação oferecida pelas instituições de educação superior e as transformações gerais da sociedade. É no contexto dessas transformações que é possível compreender a origem das diferentes iniciativas e discussões que deram início à reforma do sistema de ensino superior na Alemanha.

\section{Os argumentos para a adoção do Processo de Bolonha}

Os principais argumentos para a adoção do modelo de Bolonha basearam-se ora no reconhecimento das deficiências do ensino oferecido, ou seja, no esgotamento do antigo modelo, ora na atratividade do novo modelo proposto.

Com relação ao reconhecimento das deficiências, destacam-se os seguintes argumentos: o Diplom e o Magister representavam uma graduação muito longa e sem estrutura definida; as taxas de evasão eram altas; os custos de formação do aluno eram, portanto, também altos; o professor tinha ampla liberdade de oferecer os cursos de sua escolha sem ter de seguir um currículo 
mínimo; pouca atratividade dos cursos superiores para as novas gerações de alunos; falta de recursos financeiros; insuficiente compatibilidade internacional dos diplomas; falta de um sistema de garantia de qualidade; problemas na estruturação e na orientação de um currículo básico; crescimento da diversidade cultural e social dos estudantes e, consequentemente, de suas expectativas e potencialidades (Winter, 2009; Brändle, 2010).

Considerando a atratividade do modelo proposto, os argumentos a favor de Bolonha foram: possibilidade de reconhecimento, no contexto europeu, dos créditos e diplomas; ampliação das possibilidades internacionais de empregabilidade dos egressos; importância da mobilidade de estudantes e professores; possibilidade de aumentar a eficiência do investimento no ensino superior; construção paulatina de um Espaço Europeu de Educação Superior no qual, livre de limitações nacionais, a ciência deveria ser desenvolvida em forma de cooperação solidária (HRK, 2001).

\section{A nova estrutura do sistema de ensino superior na Alemanha}

$\mathrm{Na}$ Alemanha, a decisão de aderir ao Processo de Bolonha foi tomada em conjunto por governo federal (Bund) e governos dos estados (Länder). Assim, os principais atores desse processo foram o BMBF e a KMK. Ambas as instâncias ratificaram a participação da Alemanha no Processo de Bolonha (Neves \& Koppe, 2009).

A ideia de introduzir cursos de Bachelor e Master, no entanto, já era motivo de discussão. Em 1998, foi aprovada uma emenda à Lei de Educação Básica de Educação Superior, que permitia aos estados e às universidades a criação de outros tipos de curso de educação superior, denominados Bachelor e Master. De acordo com Witte:

A emenda à Lei Básica sobre a Educação Superior esteve sob preparação por servidores do Ministério da Educação alemão por muitos anos, mas foi somente em 1998 que o tempo de reformas na educação superior alemã chegou. Desde 1994, o ex-advogado e membro do Parlamento federal Jürgen Rüttgers havia sido ministro da Educação Superior, da Investigação e Tecnologia sob a coligação governamental conservadora/liberal liderada por Helmut Kohl. Diversos sinais de setores da educação superior, patronais, e até mesmo da oposição social-democrata/verdes, que detinha a maioria no Conselho Federal (Bundesrat), naquela época, revela que havia uma opinião pública a favor de um aumento substancial da autonomia das IES, um caráter de maior competitividade para o sistema de educação superior, bem como a possibilidade de introduzir programas de Bachelor e Master em particular (Witte, 2006a: 164).

A introdução de cláusulas de "experimentação" permitiu o funcionamento paralelo dos antigos com os novos cursos. A proposição dessa emenda à Lei Básica sobre a Educação Superior resultou de um consenso em relação à necessidade da reforma do modelo tradicional de ensino superior, considerando a baixa atratividade para os novos estudantes.

É importante salientar que a estrutura do sistema de ensino superior na Alemanha é distinta da dos demais países. Os governos estaduais têm au- 
tonomia sobre o sistema de ensino superior, o que permite diferenciação entre eles. Contudo, para a implementação da reforma, formou-se uma coalizão entre o Ministério Federal de Educação e Pesquisa, a Conferência dos Secretários da Educação e da Cultura dos estados, responsáveis pela legislação e pela regulação do ensino superior, e ainda a Conferência dos Reitores da Alemanha. Esses órgãos formaram o núcleo de concertação da reforma.

No processo de efetivação da reforma, coube à KMK um papel fundamental, por se constituir em uma esfera de discussão e de decisão que conformava as opiniões divergentes entre os estados alemães em acordos mínimos, ou consensos. Considerando que os estados mantêm sua autonomia, a KMK teve um papel estratégico para a concretização da reforma definida com o Processo de Bolonha a fim de garantir uma estrutura de ensino superior comum a todos eles.

Como as decisões no nível europeu, das quais participava apenas o BMBF, não têm força de lei, sendo, no máximo, recomendações, coube à KMK determinar as condições de implementação da reforma. Isso foi feito em relação direta com a Conferência dos Reitores, com as IES e com outros órgãos, como o Serviço Alemão de Intercâmbio Acadêmico (DAAD), o Sindicato da Educação e Ciência (GEW), entre outros. No entanto, é possível constatar que, entre os atores governamentais e as IES, produziu-se um espaço de tensões originadas em duas questões centrais: de um lado a discussão sobre a diversificação do financiamento do ensino superior; de outro, o debate sobre a autonomia das IES (Brändle, 2010: 111). Outro fator de tensão é o aumento do número de atores no processo de reforma, não mais restrito aos Estados nacionais. O envolvimento de novos atores supranacionais do âmbito europeu resultou em novas estruturas e em mecanismos de ingerência sobre as políticas dos estados e das próprias IES. Os principais são: a Comissão Europeia (European Commision) e o Conselho Europeu (Council of Europe).

A Conferência dos Reitores, que representa as universidades alemãs, manteve-se em seu papel tradicional de discussão e orientação, mas comprometendo-se claramente com os objetivos propostos pela reforma. Para apoiar as universidades, a HRK criou um Centro de Bolonha coordenado pelo Bologna Team (HRK, 2010a).

\section{O ensino superior na estrutura de ciclos na Alemanha após a reforma}

Ainda hoje permanece, em muitos cursos, uma dupla estrutura: a dos ciclos e a dos diplomas tradicionais para alunos remanescentes do antigo sistema. Também está aberta a discussão em torno dos cursos que são concluídos com o exame de Estado (Staastexam), como medicina, odontologia, veterinária, farmácia, direito, química de alimentos e formação de professores,${ }^{6}$ que permanecem no formato tradicional (Winter, 2009). 
Na Alemanha, a primeira ideia da reforma foi a de que o Bachelor deveria formar os estudantes para o mercado de trabalho e ser distinto do Master, mas não menos importante (Erichsen, 2007: 11). Todavia, é cada vez maior o número de alunos que cursam o Master, dadas as exigências do próprio mercado de trabalho. Em muitos casos, só é reconhecida, no mercado, a formação profissional com a conclusão dos dois ciclos, como ocorre com as engenharias.

É importante registrar, ainda, que a efetivação do sistema de ciclos não significou que foram introduzidos conteúdos comuns a cada ciclo. Ou seja, um Bachelor em economia, em uma universidade alemã, pode ser tão semelhante ou diferente em seu currículo quanto outro curso de Bachelor na mesma área na Alemanha ou em outro país. Os estudos são organizados em módulos que correspondem a unidades de ensino e aprendizagem definidos com base nos objetivos dos estudos (Witte, 2006b).

A Alemanha tem 394 IES, das quais 124 são universidades, 219 são escolas superiores tecnológicas e 51 são escolas superiores de arte e música. O número de alunos gira em torno de 2.025.742, sendo que 239.143 são alunos estrangeiros. Do total de alunos, 67,4\% deles estudam em universidades (HRK, 2010b).

No gráfico abaixo, é possível observar a evolução dos cursos de Bachelor e Master. O processo de substituição dos cursos tradicionais (Diplom e Magister) pelos novos cursos cresceu rapidamente a partir de 2004.

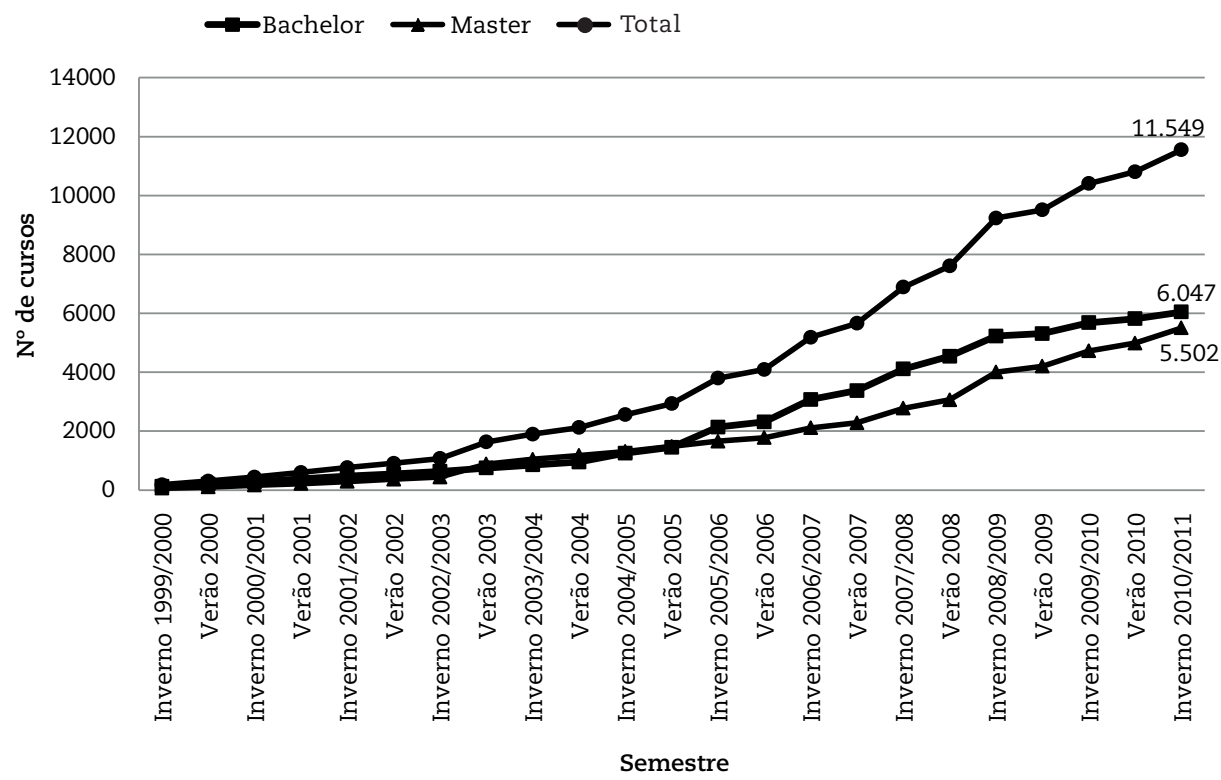

Gráfico 1 : Evolução dos novos cursos por semestre acadêmico Fonte: HRK (2010b: 8). 
Em 2004, havia 11.183 cursos no total, dos quais 19\% eram Bachelor e Master. No semestre de inverno 2010-2011, o total de cursos oferecidos foi de 14.094, dos quais 81\% correspondem a Bachelor (6.047) e a Master (5.502).

Nas universidades, $78,1 \%$ dos cursos já seguem a estrutura de ciclos. Nas escolas superiores tecnológicas, $96,8 \%$ já seguem o novo formato de $\mathrm{Ba}$ chelor e de Master. Nas escolas superiores de arte e música, o percentual gira em torno de 50\% (HRK, 2010b).

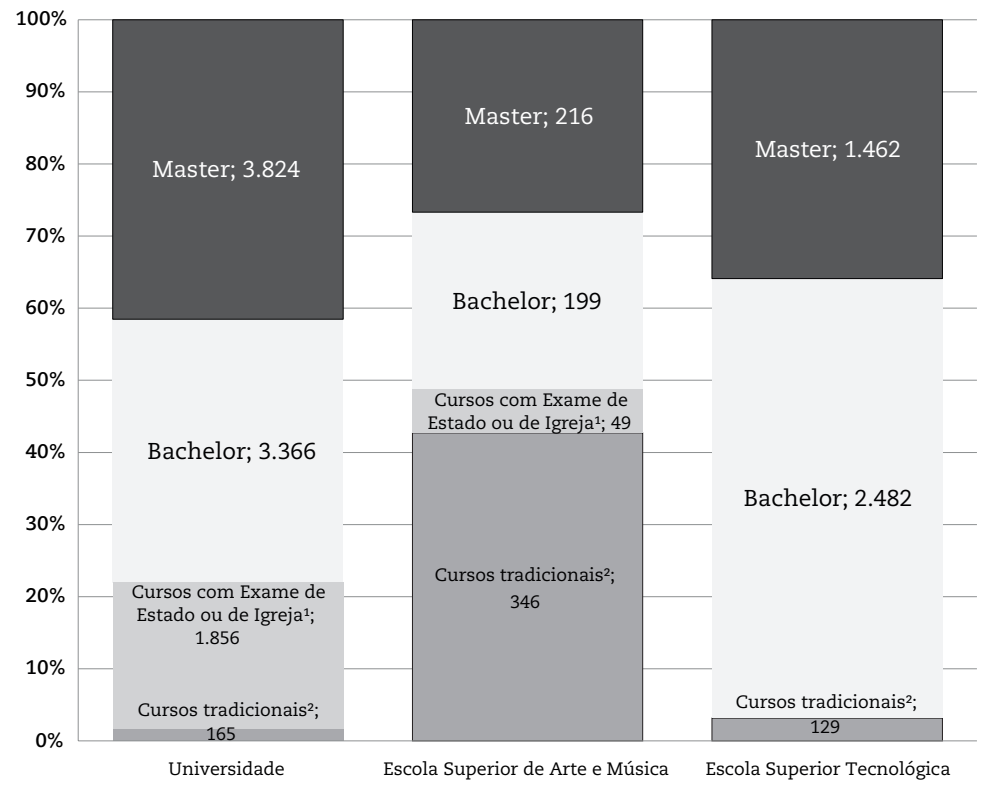

Gráfico 2: Distribuição dos cursos por tipo de instituição

${ }^{1}$ Cursos que exigem exames finais aplicados e supervisionados pelo Estado: medicina, odontologia, veterinária, farmácia, direito, química de alimentos e formação de professores; cursos que exigem exames finais aplicados pela Igreja: teologia.

2 Cursos que ainda oferecem os antigos diplomas: Diplom e Magister. Fonte: HRK (2010b: 9).

\section{Questionamentos, desafios e perspectivas}

Dez anos depois de iniciado o processo de reforma na Alemanha, o que se observa é um quadro bastante diferenciado de como os diferentes "atores" se posicionam com relação à reforma. Desde 2009, esse novo sistema vem sendo debatido de forma intensa. Tanto os organismos envolvidos com a reforma - como KMK, HRK e as próprias IES - quanto os partidos políticos vêm produzindo balanços sobre a reforma e propondo correções de rumo. Chama 
a atenção certa unanimidade, especialmente entre esses organismos, de que a reforma foi importante e de que foi uma "história de sucesso".?

Contudo, para muitos professores na Alemanha, ela é vista atualmente como um "quadro emaranhado" que precisa de ajustes. Alguns falam até da reforma da reforma, e outros mencionam que a reforma precisa ser implementada adequadamente.

Já os estudantes, em 2009, fizeram protestos e greves em diversas universidades alemãs, chamando a atenção para a excessiva burocratização da reforma, a falta de flexibilidade dos currículos, a excessiva maratona de provas e a consequente pressão sobre o desempenho. Esses protestos levaram Anette Schavan, ministra da Educação e Pesquisa da Alemanha, a reunir, em Berlim, os diferentes setores envolvidos - as IES e os estudantes - para a discussão dos problemas apontados.

A principal crítica feita diz respeito ao processo inflexível de implementação do sistema de ciclos com excessiva estruturação dos currículos e do processo de avaliação. Especialmente entre os alunos, há pressão por mais flexibilidade na auto-organização dos estudos. O estresse de concluir o Bachelor em três anos também é apontado como responsável pela pouca mobilidade dos estudantes. Outros fatores, como uma relação inadequada professor/aluno e tutorias insuficientes pela falta de professores, também são apontados como pontos críticos (Winter, 2009).

Segundo os estudos e as diversas manifestações dos organismos e das próprias IES, os desafios são muitos e fala-se na necessidade de implementar a segunda fase do Processo de Bolonha com o fortalecimento dos recursos financeiros para o ensino superior. Há uma expectativa de que as IES, por meio de sua organização interna, desenvolvam "boas práticas" e inovação no campo do ensino e da aprendizagem, garantindo a qualidade (Christoph \& Roessler, 2010). O grande desafio é aperfeiçoar a reestruturação curricular do Bachelor e do Master, fortalecendo a flexibilidade, mas mantendo a qualidade do ensino e da aprendizagem. O novo paradigma de orientação desse processo é Shift from Teaching to Learning (Wildt, 2009).

No caso da Alemanha, paralelamente à implementação da reforma preconizada por Bolonha, assiste-se também a um significativo esforço de fortalecimento da capacidade de pesquisa e de inovação. Grandes projetos federais pretendem reforçar a constituição de uma rede de universidades de excelência e as ligações entre elas e a dinâmica da economia e do desenvolvimento social. Os principais projetos são: a Iniciativa da Excelência, o Pacto da Educação Superior e o Pacto para a Pesquisa e Inovação (BMBF, 2010).

\section{Dimensão social da reforma}

A dimensão social da reforma é outro aspecto em discussão. Ela passou a fazer parte do Processo de Bolonha na Conferência de Praga em 2001. Nesse comu- 
nicado, a dimensão social foi associada ao fomento da mobilidade estudantil. Na Conferência de Bergen, em 2005, a dimensão social foi reafirmada a fim de aumentar o acesso ao ensino superior de grupos em desvantagem social e econômica, com a garantia da conclusão dos estudos para esses grupos.

Na Alemanha, o acesso ao ensino superior é garantido pela Constituição. Diversos estudos indicam, porém, que há muitos grupos com dificuldades de acesso ao ensino superior. Entre eles estão as mulheres, os jovens estudantes de famílias de baixa renda, estudantes com trajetória de migração, com deficiências, com filhos e profissionais sem diploma formal de acesso ao ensino superior (Brändle, 2010: 131). Um estudo realizado pelo Serviço de Apoio ao Estudante, de 2007, revela que o acesso ao primeiro ano no ensino superior é de apenas $18 \%$ dos candidatos cujo pai é trabalhador. Dos filhos de pais funcionários públicos, $64 \%$ dos candidatos entram no ensino superior. Cinquenta e dois por cento dos candidatos cujo pai é autônomo e 40\% cujo pai é empregado também ingressam nesse nível de ensino (Deutsches Studentenwerk, 2007).

A ampliação da dimensão social é tema de debate nos principais organismos, nas IES e entre os estudantes e suas representações. No entanto, segundo órgãos governamentais, razões estruturais e financeiras têm dificultado a ampliação do acesso (Brändle, 2010: 130). Por isso, a principal reivindicação é o aumento de recursos para as IES. A essa reivindicação somam-se a pretensão da eliminação das barreiras para conseguir uma vaga no ensino superior e a garantia das condições adequadas para o estudo, evitando, desse modo, a evasão dos alunos. Praticamente ausente do debate é a preocupação com políticas afirmativas e compensatórias.

\section{Entrada no mercado de trabalho}

Em que medida, dez anos após o início das reformas, pode-se dizer que o sistema de ciclos facilitou o acesso dos jovens ao mercado de trabalho? O ingresso nesse mercado se tornou mais rápido? Estão os jovens e os empregadores satisfeitos com o novo sistema?

Há muita polêmica em torno desses temas. Estudos e relatórios vêm revelando que ainda há muita desinformação por parte dos empregadores sobre os novos cursos e sobre as qualificações adquiridas. Na Alemanha, o ceticismo com relação aos novos cursos é maior entre os executivos de pequenas e médias empresas do que entre os grandes empregadores. Em 2004, quinze representantes de grandes empresas se pronunciaram a favor dos novos cursos por meio dos documentos Bachelor Welcome! (2004) e More Bachelors and Master Welcome! (2006) (Banscherus et al., 2009). É possível considerar que a maior aceitação dos novos cursos entre esses grandes empregadores seja resultado, precisamente, do fato de que as grandes empresas têm uma escala de operação global e, assim, avaliam a nova realidade de equivalências no âmbito europeu como mais vantajosa (Brändle, 2010: 137 ss). A crise recente e suas consequên- 
cias para o emprego é vista, de outro lado, como obstáculo para uma mais acurada avaliação da adequação dos novos ciclos de formação às necessidades do mercado de trabalho e da economia em geral.

Um estudo do Centro de Informações do Ensino Superior (HochschulInformations-System) (HIZ, 2007) revela uma diferença entre os egressos por tipo de IES. Tomando como exemplo os cursos de economia, $80 \%$ dos egressos dos cursos de Bachelor das escolas superiores tecnológicas vão diretamente para o mercado de trabalho após a conclusão do curso, e apenas $30 \%$ dos egressos de Bachelor de universidades.

Esses últimos egressos revelam mais insegurança quanto à chance de encontrar um emprego apenas com o diploma do primeiro ciclo. Por isso, tendem a seguir sua formação em um curso de Master. A busca por mais qualificação está associada, certamente, à pretensão de oportunidades de emprego mais vantajosas.

Comparando-se os egressos de Bachelor com os estudantes egressos de cursos com diploma tradicional, também foram evidentes as diferenças de trajetória. Os egressos de cursos tradicionais, em sua maioria, seguem diretamente para o mercado de trabalho (HIZ, 2007).

O balanço da primeira década de implementação das reformas desencadeadas após a primeira reunião de ministros da Educação europeus, realizada em $\mathrm{Pa}$ ris, é, segundo os principais atores envolvidos no processo, positivo. Isso não significa que todos os seus principais objetivos foram plenamente atingidos e que, em seus desdobramentos, o processo não mereça críticas. Significa que suas motivações continuam a ser reconhecidas como válidas e que a direção das mudanças é, ainda, percebida como correta.

O cenário de mudanças globais e de acirramento da competição econômica, bem como de consolidação da ideia de que o conhecimento é a base do desenvolvimento econômico e social e da capacidade de enfrentar problemas sempre mais agudos e abrangentes, tornou-se mais nítido nesses últimos dez anos. Os países da Europa e seus principais líderes mantêm a percepção de que suas chances são maiores como bloco do que na perspectiva de cada nação isolada. Assim, a construção da Área de Educação Superior Europeia e do Espaço Europeu de Pesquisa mantém a atualidade e continua a impactar a formulação de planos e de iniciativas para a região.

No caso da Alemanha, em particular, assiste-se a um significativo esforço de ajustes e correções do processo de reforma, paralelamente ao fortalecimento da capacidade de pesquisa e de inovação. 
Esse intenso e abrangente processo de reforma e essa combinação de iniciativas que visam à modernização do ensino superior, sua expansão, o aumento de eficiência, a preservação da excelência e a aproximação mais sinérgica com as expectativas da sociedade e da economia, no Brasil, podem e devem servir de estímulo para uma reflexão mais objetiva sobre nossas necessidades e possibilidades.

O tema da reforma universitária no Brasil dominou os debates sobre as perspectivas de nosso ensino superior no fim dos anos 1990 e no começo do novo século. A pretendida reforma foi substituída, contudo, por iniciativas isoladas de algumas IES e por um conjunto de iniciativas governamentais que impulsionaram os investimentos nas instituições públicas e criaram um ambiente de euforia com relação às perspectivas de expansão, de democratização do acesso e de melhoria da infraestrutura humana e material da rede de IES federais. Com isso, houve o abandono da reflexão sistemática sobre as estratégias, objetivos e metas de uma reforma mais ampla. Os novos programas passaram a ser vistos como estruturantes de um processo que deveria ter o mérito de impulsionar transformações abrangentes valendo-se de pesados investimentos no setor federal.

Não cabe, no âmbito deste artigo, analisar esses programas e seus impactos sobre o ensino superior brasileiro. Vale a pena, no entanto, registrar, neste contexto, as reações ao desenrolar do Processo de Bolonha entre nós.

No Brasil, podem-se identificar dois tipos principais de reação à Bolonha. De um lado, tem-se a rejeição radical do processo em virtude de seu caráter de reforma neoliberal. Essa crítica, ideológica e precipitada, acusa a reforma europeia de servir aos propósitos de uma economia de mercado que não conhece limites e se propõe a transformar educação em mercadoria. De outro lado, há os que encaram Bolonha como a fonte de inspiração para importantes iniciativas inovadoras no âmbito das transformações por que passa o ensino superior no Brasil. É o caso dos que entendem que os projetos da Universidade Federal do $A B C$ (UFABC), de reforma do ensino na Universidade Federal da Bahia (UFBA) e mesmo o projeto Reestruturação e Expansão das Universidades Federais (Reuni) remontam ao espírito e aos principais objetivos do Processo de Bolonha. Ambas as situações revelam desconhecimento e, no primeiro caso, também má-fé. Apenas um entendimento superficial do que se passa na Europa pode sustentar a hipótese de que aí esteja a motivação das iniciativas do segundo caso.

A precipitação e o desconhecimento não podem levar nem à rejeição ideológica despropositada nem à fácil adoção de Bolonha como referência para toda e qualquer iniciativa inovadora no nosso sistema de ensino superior.

Bolonha, como se viu, é um processo complexo e vem sendo acompanhado por discussão e estudos exaustivos e críticos, com amplo envolvimento de todos os atores responsáveis por sua implementação e pelos destinatários de seus resultados. Talvez aí esteja algo para nos servir de referência e modelo. 
Clarissa Eckert Baeta Neves é professora de Sociologia da Universidade Federal do Rio Grande do Sul (UFRGS), pesquisadora do Conselho Nacional de Desenvolvimento Científico e Tecnológico (CNPq), doutora em Sociologia pela Universidade de Münster-Alemanha e coordenadora de um grupo de estudos sobre universidade. É também membro da comissão editorial da Revista Sociologias (UFRGS) e do Comitê de Avaliação do CNPq. Foi pesquisadora visitante na Universidade de Münster com apoio do Serviço Alemão de Intercâmbio Acadêmico (DAAD) e da Coordenação de Aperfeiçoamento de Pessoal com Nível Superior (Capes) (2011). Tem produção científica destacada em sociologia da educação e em educação superior. 


\section{NOTAS}

1 Agradeço à Coordenação de Aperfeiçoamento de Pessoal com Nível Superior (Capes) e ao Serviço Alemão de Intercâmbio Acadêmico (DAAD) o apoio para a realização de uma missão de pesquisa na Universidade de Münster em janeiro de 2011, com o objetivo de estudar a Reforma de Bolonha. Nesse período, tive a oportunidade de realizar entrevistas com administradores, professores e estudantes da universidade, bem como acessar importantes bases de dados e documentos nos diferentes órgãos responsáveis pela reforma. Destaco ainda o contato estabelecido com o diretor do Bologna Team da Conferência dos Reitores da Alemanha.

2 O Programa Sócrates foi criado em 1994 com o objetivo de promover a mobilidade por meio da educação. Em 2007, foi substituído pelo Lifelong Learning Programme 2007-2013.

3 Protocolo Erasmus, ou Programa Erasmus, foi estabelecido em 1987. É um programa de apoio interuniversitário de mobilidade de estudantes e docentes do ensino superior entre Estados-membros da UE e estados associados. Permite a alunos estudar em outro país por um período de três meses a um ano.

4 O BFuG é uma estrutura de acompanhamento permanente e de desenvolvimento do Processo de Bolonha, criado na Conferência de Praga, em 2001. É composto de representantes de todos os países participantes juntamente com a Comissão Europeia. Na Conferência de Bergen, em 2005, o BFuG foi incumbido de várias missões, das quais se destacam o estabelecimento de critérios de qualidade do ensino, o estabelecimento e o reconhecimento de graus acadêmicos e a criação de sistemas de reconhecimento de competências.

5 Informação obtida em entrevista realizada com o professor Erichsen (ex-reitor da Westfälischen Wilhelms-Universität Münster - WWU), na Universidade de Münster, em 12 de janeiro de 2011.

6 A maioria dos cursos de formação de professores (2.508) segue sendo oferecida na forma tradicional, exigindo o exame de Estado. Em 2010, apenas 34,2\% (857) dos cursos foram reestruturados como Bachelor, devendo ser seguidos por um curso Master (HRK, 2010b). 
7 Informação obtida em entrevista realizada com o dr. Peter A. Zervakis, coordenador do Centro de Bolonha da Conferência de Reitores da Alemanha, em Bonn, em 21 de fevereiro de 2011.

\section{REFERÊNCIAS BIBLIOGRÁFICAS:}

Altbach, Philip G.; Reisberg, Liz \& Rumbley, Laura E. Trends in Global Higher Education: Tracking an Academic Revolution.

Chestnut Hill/Boston: College Center for International Higher Education, 2009.

Banscherus, Ulf et al. Der Bologna-Prozess zwischen Anspruch und Wirklichkeit. Frankfurt: Gewerkschaft Erziehung und Wissenschaft, 2009.

Bergen Communiqué, 2005. Disponível em <http://www.ond. vlaanderen.be/hogeronderwijs/bologna/documents/MDC/ 050520_Bergen_Communique.pdf $>$. Acesso em 17 jan. 2011.

Berlin Communiqué, 2003. Disponível em <http://www.ond. vlaanderen.be/hogeronderwijs/bologna/documents/MDC/ Berlin_Communique1.pdf>. Acesso em 17 jan. 2011.

BMBF (Bundesministerium für Bildung und Forschung). Bundesbericht Forschung und Innovation, 2010. Disponível em <http://www.bmbf.de/>. Acesso em 15 fev. 2011.

Bologna Declaration, 1999. Disponível em <http://www.ond. vlaanderen.be/hogeronderwijs/bologna/documents/MDC/ BOLOGNA_DECLARATION1.pdf >. Acesso em 12 jan. 2011.

Brändle, Tobias. 10 Jahre Bologna-Prozess. Wiesbaden: VS Research, 2010.

Budapest-Vienna Declaration, 2010. Disponível em <http:// www.ond.vlaanderen.be/hogeronderwijs/bologna/2010_ conference/>. Acesso em 8 fev. 2010.

Christoph, Gabriela \& Roessler, Isabel. Bachelor auf Erfolgskurs!? Arbeitspapier, CHE/Centrum für Hochschulentwicklung, 2010, 134.

Conselho Europeu de Lisboa. Estratégia de Lisboa, 2000. Disponível em <http://www.gpeari.mctes.pt/archive/doc/ EstrategiaLisboa.pdf>. Acesso em 15 jan. 2011. 
Conselho da União Europeia. Agenda de Modernização das Universidades, 2007. Disponível em <http://register.consilium.europa.eu/pdf/pt/07/st16/st16096-re01.pt07.pdf>. Acesso em 15 jan. 2011.

Council of Europe. Higher education and Research. Disponível em <http://www.coe.int/t/dg4/highereducation/ default_EN.asp?>. Acesso em 15 fev. 2011

Deutsches Studentenwerk. Die Wirtschaftliche und soziale Lage der Studierenden in der Bundesrepublick Deutschland, 2007. ECTS (European Credit Transfer System), 2004. Disponível em <http://ec.europa.eu/dgs/education_culture/publ/pdf/ ects/en.pdf >. Acesso em 13 jan. 2011.

ENQA (European Association for Quality Assurance in Higher Education). European Standards and Guidelines for Quality Assurance in the European Higher Education Area, 2005. Disponível em <http://www.enqa.eu/files/ENQA\%20 Bergen\%20Report.pdf>. Acesso em 12 fev. 2011.

Erasmus Programme, 2010. Disponível em <http://ec.europa.eu/education/erasmus/doc/stat/report0809.pdf>. Ver também <http://ec.europa.eu/education/programmes/llp/ erasmus/statisti/table1.pdf>. Acesso em 12 fev. 2011.

Erichsen, Hans-Uwe. Tendências Europeias na graduação e na garantia da qualidade. Sociologias, jan./jun. 2007, 9/17, p. 22-49.

European Student's Union, 2006. Disponível em <http:// www.letsgocampaign.net/>. Acesso em 12 fev. 2011.

Eurydice/EACEA, 2010. Network on Education Systems and Policies in Europe. Disponível em <http://eacea.ec.europa.eu/ education/eurydice/index_en.php>. Acesso em 13. jan. 2011. Frey, Rainer. Tradition und Neugesatltung der deutschen Universität. Bologna-Reform als Irrweg? Palestra realizada na UFRGS, Porto Alegre, 20 nov. 2009.

HIZ (Hochschul-Informations-System). Bachelor! was sonst? Hisbuskurz-Information, 2007, n. 17. Disponível em <http:// hisbus.hiz.de/hisbus/docs/.hisbus17.pdf>. Acesso em 11 jan. 2011.

HRK (Hochschulrektorenkonferenz). Deutschland im europäischen Hochschulraum-Plenar-Entschließung der HRK zu den Schlussfolgerungen aus der Bologna-Erklärung, 
2001. Disponível em <http://www.hrk.de/de/beschluesse/ 109_323.php>. Acesso em 13 jan. 2011.

Bologna Zentrum, 2010a. Disponível em <http:// www.hrk-bologna.de/bologna/de/index.php>. Acesso em 15 jan. 2011.

Statistische Daten zur Einführung von Bachelor-Masterstudiengängen Wintersemester 2010/2011. Statistiken zur Hochschulpolitik. Bonn, 2010 b. Disponível em <http:// www.hrk.de/de/download/dateien/HRK_StatistikBA_MA_ WiSe_2010_11_final.pdf>. Acesso em 12 fev. 2011.

London Communiqué, 2007. Disponível em <http://www. ond.vlaanderen.be/hogeronderwijs/bologna/documents/ MDC/London_Communique18May2007.pdf>. Acesso em 12 jan. 2011.

Ministry of Science, Technology and Innovation, 2005. The Framework of Qualifications for the European Higher Education Area. Disponível em <http://www.ond.vlaanderen. be/hogeronderwijs/bologna/documents/QF-EHEA-May2005. pdf $>$. Acesso em 18 jan. 2011.

Morhard, Bettina. Lehren und Lernen mit ERASMUS in Europa. Bonn: DAAD, 2005.

Neves, Clarissa Eckert Baeta. Universidade e a institucionalização da pesquisa: reflexões de uma experiência. Cadernos de Sociologia, 1998, 8, p. 127-160.

\& Koppe, Leonardo Renner. Processo de Bolonha: a reforma do sistema de educação superior europeu. Tomo: Revista do Núcleo de Pós-Graduação e Pesquisa em Ciências Sociais da Universidade Federal de Sergipe, jul./dez. 2009, 15, p. $15-39$.

Nybom, Thorsten. The Humboldt Legacy: Reflections on the Past, Present, and Future of the European University. Higher Education Policy, 16/2, 2003, p. 141-159.

Prague Communiqué, 2001. Disponível em <http://www. ond.vlaanderen.be/hogeronderwijs/bologna/documents/ MDC/PRAGUE_COMMUNIQUÉ pdf>. Acesso em 12 jan. 2011. Sorbonne Joint Declaration, 1998. Disponível em <http:// www.ond.vlaanderen.be/hogeronderwijs/bologna/documents/MDC/SORBONNE_DECLARATION1.pdf > . Acesso em 11 jan. 2011. 
Teichler, Ulrich \& Wasser, Hans (orgs.). American and German Universities. Kassel: Werkstattbericht, 1992.

Wildt, Johannes. Die Zukunft von Bologna: Thesen aus der Sicht der Hochschuldidaktik. In: 10 Jahre nach Bologna: Bachelor und Master auf dem Prüfstand. Dokumentation der Veranstaltung. Grüne im Landtag NRW, 2009, p. 29-34.

Winter, Martin. Das neue Studieren: Chancen, Risiken, Nebenwirkungen der Studienstrukturreform: Zwischenbilanz zum Bologna-Prozess in Deutschland. Arbeitsbericht/Institut für Hochschulforschung (HoF), 2009, 1/9.

Witte, Johanna. Change of degrees and degrees of change: comparing adaptations of european higher education systems in the context of the bologna process. Enschede: CHEPS/UT, 2006a. Disponível em <http://www.utwente.nl/cheps/documente $\mathrm{n} / 2006$ wittedissertation.pdf $>$.

. Die deutsche Umsetzung des Bologna-Prozesses. Aus Politik und Zeitgeschichte, 2006 b, 56/48, p. 21-27. Disponível em <http://www.bpb.de/files/X9FKNO.pdf>. Acesso em 20 jan. 2011. 


\section{Palavras-chave: Resumo:}

Ensino superior; Este artigo trata da implementação do Processo de Bolonha Processo de Bolonha; iniciado em 1998. Tal processo consiste em uma ampla rePolíticas de educação; forma da educação superior na Europa. Após se examinar Ensino superior na Alemanha; a trajetória de consolidação dos objetivos e as metas desse Ensino superior na Europa. programa, é focalizada, privilegiadamente, a situação atual do ensino superior na Alemanha. São abordados três aspectos centrais: o processo de formulação de uma reforma de proporções continentais por meio das conferências e dos comunicados; as mudanças introduzidas na organização do ensino superior; e, por fim, a análise do processo de adoção do modelo Bolonha no sistema de ensino superior na Alemanha e os problemas e desafios dez anos depois.

\section{Keywords: Abstract:}

Higher education;

This article deals with the implementation of the Bologna Bologna Process; Process, which began in 1998. This process consists of a

Education policy; comprehensive reform of higher education in Europe. After

Higher education in Germany; examining the trajectory for consolidating the objectives Higher education in Europe. and goals of this program, the current situation of higher education in Germany is focused. Three aspects are central: the process of formulating a reform of continental proportions by means of conferences and releases, the changes at the organization of higher education and, finally, the analysis of the process of adopting Bologna model in higher educational system in Germany and the problems and challenges after ten years. 